\title{
Forestry operations into the next century ${ }^{1}$
}

\author{
by Daniel Y. Guimier ${ }^{2}$, Eng. and Ernest Heidersdorf, ${ }^{3}$ Eng.
}

\section{Introduction}

We are living in an age when change is accelerating and the only thing that we can really predict is that tomorrow will be different from today. Even though the underlying natural rhythms of the forest's evolution are dictated by Mother Nature, and remain unchanged and largely invisible even to forestry experts, forestry activities are undergoing a revolution. In this light, what will future forestry operations resemble in the next century? In what context will workers, technicians and forestry managers work? It would be presumptuous to attempt to predict this with any certainty, but an analysis of the technical, social, and economic factors the forest industry currently faces can nonetheless help us to predict how operations will have to change to adapt to future demands. The beauty of predicting the future is that nobody today can prove that we're wrong; it will be interesting to reread this text in five or ten years to compare our predictions with reality!

In this context, our presentation will focus on outlining what forestry operations will be like in the year 2000 and beyond, based on the factors that are driving change ("driving forces") that we can perceive today. We will start with a definition of those factors that are evident at local and international scales, from both a technical and an economical view and in a human context, after which we will discuss how forestry activities and equipment must adapt to these changes.

This presentation is based on a strategic "orientation" exercise that FERIC recently completed on behalf of Industry Canada with the assistance of our members. This exercise, entitled "Technology Road Map for Forest Operations in Canada", had the goal of formulating recommendations for governments, the forest industry, equipment manufacturers, research groups, and others involved in the forestry sector, and was intended to focus action on the sector's future priorities (FERIC 1996). To do so, an exhaustive review of current trends was carried out through group discussions, a literature review, and interviews with key personnel in the sector. The most promising emerging technologies were identified, and the identification of technological or organisational gaps subsequently helped to define the road or roads along which the "road map" would lead to prosperous forest operations in the next century.

\section{Forces of Change}

We identified nine groups of factors that, together, affect and will continue to affect future forestry operations:

- the delivered cost of fibre,

\footnotetext{
${ }^{1}$ Presentation to the Joint Session of Sustainable Site Productivity in Canadian Forests Workshop and Ontario Professional Foresters Association Annual Meeting, Sault Ste. Marie, Ontario, 20 February 1997.

${ }^{2}$ Manager-Eastern Division, Forest Engineering Research Institute of Canada (FERIC), 580 boul. Saint-Jean, Pointe-Claire, Quebec H9R 3J9.

${ }^{3}$ Research Director-Eastern Division, Forest Engineering Research Institute of Canada (FERIC), 580 boul. Saint-Jean, Pointe-Claire, Quebec H9R 3J9.
}

- environmental isues,

- resource availability,

- the profile of the operations and operators,

- government involvement,

- public pressures,

- worker needs,

- market demands, and

- technological innovations.

Most of these factors are interrelated and act together; for example, public pressures influence government involvement, and environmental issues have an impact on market demands. Some of these factors act in concert whereas others conflict; for example, environmental issues can impose financial constraints that act against the need to reduce costs and remain competitive. No matter their relative importance and how they act, the following driving forces are generally recognized as primary elements of change, and will significantly affect forestry operations of the future.

\section{The Delivered Cost of Fibre}

The delivered cost of fibre is often the main component of a product's total cost. Thus, costs must be maintained at the lowest possible level for the industry to retain or regain its competitiveness against international competition that will only increase in the future. Technological and operational changes in harvesting, silviculture and transportation are thus often largely driven by the need to reduce costs.

\section{Environmental Issues}

We are all aware of our collective responsibility to conduct forestry operations that respect the environment within the context of sustainable management. Whether from the point of view of water quality, wildlife preservation, biodiversity, or aesthetics, future forestry operations must evolve in response to society's growing expectations. Planning, forestry practices, and equipment must be modified as a result.

\section{Resource Availability}

Our forests are a renewable but not inexhaustible source of raw material. Healthy management practices and the pressures from other users of the forest, specifically the general public, require that losses and wasteful practices be eliminated and that good use by made of all the available fibre. In some areas, we are already experiencing shortages of fibre in certain quality classes, and this has led to changes in our forestry practices towards techniques that further favour the recovery and use of species that were formerly considered noncommercial. In addition, increasing attention is being devoted towards making the processing phases contribute as much as possible to quality, and thus to the value of the end product.

\section{The Profile of Operations and Operators}

The structure of the forest industry itself greatly influences the nature of forestry operations. For example, a trend that began 
a few years ago and that is common today, towards contractor-based operations rather than company-owned equipment, imposes certain practices that are adapted to the needs of contractors. The need for direct and constant communication and monitoring at all levels of operations also determines the appropriate equipment and organisational structures.

\section{Government Involvement}

Governments play a major role in directing forestry practices, whether through forest practices standards and regulations, land tenure and harvesting policies, environmental laws, or other legislation (or lack thereof), and they will continue to play this role in the future. Whether they fulfill this role via incentives or coercion, the policies by which they act will have a decisive influence on the equipment and operational techniques used in the forest. In addition, workers and forest managers must, more than ever, understand and apply these increasingly complicated laws.

\section{Public Pressures}

The public comprises an increasingly important driving force. Not only does the public participate in public consultations in specific cases (as in the case of Clayoquot Sound), but there is also an increasing and unremitting role in daily decision-making and the planning of forestry operations. Whether in terms of questions such as clearcutting, monocultures, prescribed burning, roads, pesticides, or roadside debris, the public has the power to shape future practices.

\section{Worker Needs}

There is already an anticipated scarcity of qualified forest workers and this trend cannot be reversed unless forestry jobs of the future offer attractive working conditions. Moreover, some form of modified education must be provided to train operators to deal with the demands of the increasingly complex machinery and operating conditions. Even though operators have some ability to adapt to technological changes, technology itself must also be adapted to meet the needs of the available workers.

\section{Market Demands}

The globalization of markets and fierce competition for raw materials have motivated the industry to seek markets for new, more specialized products. Just as markets dictate the nature of the products that the industry manufactures, so too do the products dictate the nature and the quality of the raw material that is required. Market demands thus determine the nature of operations in the forest to some extent.

\section{Technological Innovations}

The arrival of new, innovative technologies is another source of change. If it is true that the factors we've previously cited are the engines of technological evolution, it is also true that the availability of the technology itself will lead to changes in forestry operations. For example, global positioning systems (GPS) were not invented to address a specific forestry need, but because of their availability, they have revolutionized some of our operating techniques. Undoubtedly, other technological innovations outside the forestry sector will change our way of working in the future.

\section{Trends in Various Systems \\ Harvesting Systems}

Gingras and Ryans (1992) studied the evolution in eastern Canada of the three main harvesting systems, namely, full-tree harvesting with roadside delimbing, tree-length harvesting with delimbing at the stump, and shortwood harvesting using cut-to-length machines with multi-functional heads. The current trend suggests that machines with multi-functional heads will continue to replace full-tree systems over the next five years. Many of the previously discussed factors that are driving changes, such as fibre recovery and quality, reduced environmental impacts, and increased operational flexibility, explain this trend. Another trend is becoming apparent in the form of increased harvest volumes from partial cutting. A recent survey indicated that $25 \%$ of FERIC's member companies are already performing commercial thinning, at least in the form of operational trials, and an additional $34 \%$ expect to do so over the next five years. Partial-cutting techniques will be refined in the Canadian context and applied on a wider scale in the next century.

\section{Silvicultural Systems}

A growing trend towards protecting and promoting advance regeneration will dominate in the next century. In general, silvicultural systems will tend towards encouraging the natural evolution of the forest rather than imposing an artificial approach. The areas to be planted will continue to decrease. Herbicides and pesticides will become increasingly unacceptable means of intervention, even where they are not actually prohibited, and other means of intervention will be developed. The demand for fibre and the need to protect investments will allow companies to justify stand tending operations, especially for stands near mills. Precommercial thinning operations will increase in popularity.

\section{Transportation Systems}

It may be a lack of vision, but it is hard to imagine that transportation from the forest to the mill will be performed by any means other than trucking over the next decade. One can imagine an increased use of rail transportation, aerial systems (balloons), pipelines for chips, or a modernized form of water transportation, but these are relatively improbable solutions. In contrast, the semi-trailer system will continue to evolve so as to increase its efficiency and safety. Important gains can result from increasing payload while respecting regulations on total or axle weights, as well as from more efficient motors that provide substantial fuel savings.

It is perhaps at the level of forest road construction and maintenance that the evolution has been most striking. In effect, we are approaching a situation in which the road network is already fairly well developed and the priorities will change to focus on maintenance and management of the established network rather than on its establishment. Further, the design and construction of roads must be integrated with reliable systems of preventing erosion and the consequent sedimentation of streams.

\section{Advanced Technologies}

Having presented this general overview of the evolution of various systems, let us move on to examine various recent or advanced technologies that could increasingly be applied in for- 
est operations or equipment. FERIC has identified ten of these technologies that, in our opinion, will be a significant part of the life of a forestry worker in the next century:

- machine-control systems,

- operator aids/robotics,

- lightweight components,

- positioning systems,

- computerized decision-support systems,

- training simulators,

- machine vision,

- environmentally friendly fluids,

- environmental technologies for soil protection, and

- communications.

\section{Machine-control Systems}

The machines of the future will be equipped with "intelligent" control systems that let them adapt to the environment in which they are working; by using various sensors, the machine will "know" when it is on a slope, when it is on wet ground, or when its wheels are slipping. It can thus adapt to these conditions in such a manner as to optimize its performance and reduce its impact on its environment. For example, controlling wheel slip will reduce soil damage, cabs can automatically adjust themselves to account for slopes, and an understanding of ground firmness would let a planting machine adjust planting depth for seedlings. A machine could even provide its operator with diagnostics on its operating condition, thus reducing downtime due to repairs.

\section{Operator Aids/Robotics}

As a result of automating a machine's functions, operators could concentrate their energy and resources on making strategic decisions rather than on routine operating tasks. After an initial learning phase, the machine would manage systematic and repetitive actions by itself. These could include placing logs in piles, grabbing a tree for delimbing, or moving in a straight line. Current efforts in this area focus largely on the development of a boom-control system based on coordinated motion control. This system lets the operator control the implement (e.g., a felling head) by using a mini-joystick, without having to worry about the operation of its hydraulic cylinders. In such a system, the operator simply points the control lever in the desired direction and the onboard computer controls the necessary hydraulic valves. Moving from this point to a fully autonomous robot in the forest represents an unlikely step. Even if certain activities will be highly automated, the operator will retain an important role for the foreseeable future.

\section{Lightweight Components}

There are two main reasons to reduce the weight of the components of forestry machines: to increase their payload or capacity, and to reduce ground pressure as much as possible, thus reducing the impact on the soil. The systems used in forestry operations have traditionally made little use of lightweight materials developed in other sectors such as the aerospace industry. Aluminum, Kevlar, carbon fibre, and other materials permit the construction of very strong, light components, and will be widely used in forestry equipment in the next century. Several examples are currently under development.

To work in sensitive areas such as riparian zones, where travel by forestry machinery must be avoided, operators of cable skidders can use synthetic-fibre cables rather than steel. These cables are as strong as steel, but have much lower weights, which lets operators haul out the cables much further from the machine and thus reduce the need for on-site travel.

To maximize the protection of regeneration and soils, harvesting equipment will need to have the greatest possible boom reach so as to let operators maximize the spacing between skid trails. Telescoping or unusually long booms are beginning to appear, and the use of composite materials may permit even greater lengths.

\section{Positioning Systems}

Global positioning systems (GPS) technology now lets users rapidly update maps and other forestry data, and efficiently perform on-site surveys, which formerly required considerable time and resources.

The machines of the year 2000 and beyond may be equipped with navigation systems based on GPS technology to facilitate the conduct and monitoring of harvesting and stand-tending operations. The operator can navigate using a map displayed on a screen in the cab. Navigation systems will eliminate several costs related to the demarcation of blocks, reserves, streams and roads.

However, this assumes that our basemaps have the required degree of precision and that the computerized spatial reference information will be reliable, which is not currently the case. In this context, better survey data and remote sensing will play a key role.

\section{Computerized Decision-support Systems}

With increasingly strict standards and the consideration of alternative (non-timber) values, the industry must face an increasingly complex planning process for its forest interventions. In addition, a considerable quantity of biophysical, ecology and social data will have to be available for integration in the planning process.

These are ruled by complex interrelations that will be better understood and better integrated within more precise, but not yet perfect, models. Geographic information systems (GIS) are already operational tools that greatly facilitate the management of large quantities of information. In contrast, managers have relatively few decision-support tools available to help them select an optimum harvesting and silviculture scenario. FERIC is currently working to develop a computerized model called "Interface" that will let managers simulate various harvesting and regeneration scenarios and calculate their total cost.

Similar decision-support tools will be available in the future for optimizing forestry operations in terms of environmental, ecological, social, wildlife, and other parameters. Forestry managers will still make the final decisions, but formulating the elements of a solution will be greatly simplified by the use of such computerized tools.

\section{Training Simulators}

The need for training machine operators will only increase with increasing constraints and operational demands in the forest, and with increasing complexity of forestry equipment. Because of the high cost of such equipment, the risks involved in using an inexperienced operator in the field, and the complexity of the concepts to be taught, training will rely more and more on simulators. FERIC, along with our partners in the ATREF (appli- 
cation of robotics technologies to forestry machines) project, is already working on the development of a simulator that will help operators learn to use a harvester's boom.

\section{Machine Vision}

Most future equipment will incorporate some form of machine vision that will let it evaluate the objects it must handle (trees, logs, chips, etc.) and respond appropriately. For example, FERIC foresees the development of a camera system for measuring logs on delimbers or processors. Analysing an object, as in the case of determining tree diameter, will help to optimize slashing. The same technology will be developed for measuring logs (while accounting for various deductions for rot, etc.), as well as for the analysis and sorting of pulp chips. Finally, if we hope to automate certain forestry operations (e.g., through robotics), the machine must be able to "visualize" its environment. For example, it must be capable of "seeing" a tree before it can grab it. Such machine vision systems are already well implemented in facilities such as sawmills, but will have to be adapted to the constraints of the forest environment.

\section{Environmentally Friendly Fluids}

Forestry equipment should never be a source of contamination of the water table or the atmosphere. Hydraulic, cooling, and combustion systems should be "tight" and should incorporate some mechanism for handling spills. Exhaust gases must meet strict standards, and fluids (oils, liquid coolants, fuels) will need to be biodegradable. We are already seeing the emergence of some of these products on the market. For example, vegetable oils can now replace mineral oils for lubricating the chain saws of multi-functional heads (Makkonen 1994). Soon, this type of oil will also be able to replace the hydraulic oils in forest machines.

\section{Environmental Technologies for Soil Protection}

Over the next decade, we will see the introduction of many innovations intended to reduce the impact of machinery on soils. These innovations will apply to existing traction systems or will involve new traction systems. One technology that is currently well developed, oversize tires and tracks, contributes to reducing soil compaction and rutting, and improves the flotation of forestry machines. We will also see wider use of central tire inflation (CTI) on most forestry equipment. This technology is already well developed in the trucking sector. The technology involved in "walking machines" is still at an embryonic stage, but may one day replace wheels and tracks, which are responsible for most soil disturbance. The development of each of these systems relies on a better understanding of the terra mechanics of forest soils (i.e., the interaction between wheels and the soil), a science that is still largely unknown today.

\section{Communications}

In the year 2000 and beyond, our current means of communication will appear archaic to us. For example, the Internet is only beginning to show its potential. Oral communication and the transfer of large amounts of data and images between the forestry worker, the site foreman, and the mill and its clients, will be easy and free from obstacles. The efficiency of an operation will rest, to a large degree, on good communication between the various parties involved in the forest, and modern communication tools will be increasingly available. For example, it is highly likely that a client in Copenhagen will be able to send an order for sawlogs to a mill in Thunder Bay, which will relay the species and size specifications to an operator in the forest, who can program his onboard computer to accommodate the order.

The foreman could also check the status of distant equipment and know, for example, the position of a truck, the fuel level in a harvester, or the area treated by a scarifier.

Some foresters from the British Columbia government already use a portable office that gives them access from their truck, via modem, to information such as digitized maps of a region, databases, and the text of applicable forestry practices codes.

Modernisation of our means of communication will surely rely on the development and use of a network of satellites such as MSAT and the development of standard data-exchange protocols.

\section{Conclusions}

The important pressures and trends that will shape forestry operations in the next century are already in place. The challenges that they represent will be partially solved by the use of modern technologies applied to our tools and our management and communication methods. But these technologies will provide only a support on which the worker and the forest manager can learn to accomplish their work according to the "rules of the art". The forest manager of the next century will have to be capable of making decisions that extend beyond a strictly forestry context.

Significant changes are thus expected in forestry operations, and these changes will to a large extent be imposed by necessity. It is, however, urgent that the forest sector readies itself to recognize this need to evolve, and ensures that the necessary research and development efforts are undertaken.

\section{References}

FERIC 1996. Technology road map for forest operations in Canada. For. Eng. Res. Inst. Can. (FERIC), Pointe-Claire, Que. Special Report SR-117. 15 p.

Gingras, J.-F. and M. Ryans. 1992. Future woodlands equipment needs in eastern Canada: 1992-2001. For. Eng. Res. Inst. Can. (FERIC), Pointe-Claire, Que. Tech. Note TN-193. 12 p.

Makkonen, I. 1994. Environmentally compatible oils. For. Eng. Res. Inst. Can. (FERIC), Pointe-Claire, Que. Field Note No. General$39.2 \mathrm{p}$. 